\title{
Utilization of Citrullus colocynthis as Antibacterial Activity, Antioxidant and Food Preservation in Beef Luncheon Roll
}

\section{Sabria A. Hassan' ${ }^{1}$ and Marwa Abu Sreea}

\author{
${ }^{1}$ Food Technology Department, Arid Lands Cultivation Research Institute, City for Scientific Research \\ and Technological Applications, Alexandria, Egypt. \\ ${ }^{2}$ Genetic Engineering and Biotechnology Research Institute, City for Scientific Research and \\ Technology Applications (SRTA-City), New Borg El Arab, Alexandria.
}

\author{
Received: 15 Sept. 2019/Accepted 20 Nov. 2019 / Publication date: 30 Dec. 2019
}

\begin{abstract}
Citrullus colocynthus (CCE) consider as a promising medicinal fruit, which full of rich source of natural components. This study was investigated the effect of different extraction time of aqueous CME on antioxidants, antimicrobial, cytotoxicity components, and applied in luncheon. Results reveal that the aqueous CCE was rich in phenolic compounds, flavonoids, tannins, with higher antioxidants activity, besides has potential power against pathogenic bacteria and oxidative stress. Also, appeared high safety of CCE1 and CCE2 sample of CCE at the face of wi-38 and vero normal cell line. Nevertheless, CCE1\&2 could be applied as food supplement in luncheon as antioxidant and food preservation from pathogenic bacteria .It has acceptable sensory evaluation similar to control luncheon sample.
\end{abstract}

Keywords: Citrullus colocynthus (CCE) or (Citrus melon) aqueous CME, antioxidants, antimicrobial activity, sensory evaluation, wi-38 \& vero normal cell line.

\section{Introduction}

The Citrullus colocynthis L. (bitter apple) is a desert plant and distributed in the Sahara, Egypt in Mediterranean, (Gurudeeban et al., 2011; Jayaraman and Christina, 2013). The Phytochemical analysis of plant extracts revealed the presence of carbohydrate, protein, separated amino acid, tannins, saponins, phenolic, flavonoids, terpenoids, alkaloids, anthranol, steroids, Cucurbitacin A, B, C, D, E ( $\alpha$-elaterin), J, L, caffeic acid and cardic glycoloids (Alhajjaj et al., 2010). The plant has also many using of traditional medicinal of digestive system diseases, diabetes, gastroenteritis, Constipation, dysentery and various bacterial infection. Also it used as antioxidant, analgesic, hypolipidemic, blood glucose-lowering effect, antimicrobial and anti-inflammatory affect. It has significant cytotoxic activity against human cancer cell lines of HL-60. The results from the present animal study showed that $C$. colocyn fruit, through its antioxidant and blood glucose-lowering activity, and a positive effect on the treatment of DN (Hassain et al., 2014; Mohadesh et al., 2020). Citrullus colocynthis extract for 7 day obviously reduced the impact of carbon tetrachloride toxicity on the serum markers of liver damage with ethyl acetate and chloroform and could protect liver against injury (Yangetal, 2013). CC natural, very cheap plants was used as adsorbent for phenol removal and it remove $70 \%$ of phenol per $30 \mathrm{~min}$ .It showed high affinity of waste ash adsorption which mainly composed of $\mathrm{SiO}_{2}, \mathrm{Al}_{2} \mathrm{O}_{3}$ and $\mathrm{MgO}$ (Mehdi et al., 2018). It displayed analgesic at different doses without inducing acute toxicity. Topic results were showed using of CC immature followed by seeds, the stem and root extracts to possess appeared less significant inhibitory activity against analgesic and anti-inflammatory models respectively (Belsem et al., 2010). CC form extracts types which was used in 36 studies were (ethanolic, aqueous, methanolic, hydroalco- holic, hydro-ethanol, chloroform, alkaloids, glycosidic, ethyl acetate, petroleum ether, saponosides, $\mathrm{H}_{2} \mathrm{O}$-methanol, and n-butanol), but the aqueous extract was the most frequent one. The Citrullus colocynthis dose was $300 \mathrm{mg} / \mathrm{kg}$ body weight/day most common of diabetes in 12 studies, Rats were the subject of almost all studies except eight of them, including rabbits (four studies), mice (one study), and dog (one study) (Mojtaba, et al. 2019). Citrullus colocynthis samples have inhibition effect on Bacillus curuse, Staphylococcus aureus, Escherichia coli, clostridium strains (Alhejjaj et al., 2010)

Corresponding Author: Sabria A. Hassan, Food Technology Department, Arid Lands Cultivation Research Institute, City for Scientific Research and Technological Applications, Alexandria, Egypt. E-mail: sabriaabouzeid99@gmail.com 


\section{Materials and Methods}

\section{The Citrullus colocynthus extraction:}

The Citrullus colocynthus (CC) fruit extracts were performed as follow:

Five hundred gram of bitter CC fruit were purchase from Egyptian local market and was cleaned perfectly from any dust or foreign substances. Fruits were washed with tap water and dried between two filter paper. Next seeds were isolated from fibers. After that, $560 \mathrm{ml}$ distilled water were added to seeds contents and let stand overnight, then filtered using whatt man filter papers. The resultant filtrate is considered as sample CME1. The residual seeds and pulp covered with another $569 \mathrm{ml} \mathrm{DW}$ and boiled for $30 \mathrm{~min}$, after cooling to the room temperature hot solution was filtered into clean flask and the filtrate consider as CME2. The residual from previous step re-boiled again with another $560 \mathrm{ml} \mathrm{DW}$ the filter into new clean flask and the fourth filtrate consider ad as CME3, CME4. Repeated the last treatment on CC fiber $(\mathrm{F} 1,2,3,4)$ According to Mojtaba et al. (2019).

\section{Determination of cytotoxicity effect of $C$. colocynthis fruit extract using MTT assay}

Human normal fetal lung cell line (Wi-38) and normal adult African green monkey kidney cell line (Vero) were used to investigate toxicity of C. colocynthis fruit extract according to method described by Mosmann (1983). Human Wi-38 and mammalian Vero cells were maintained in DMEM medium (Lonza, USA) containing 10\% fetal bovine serum. These cell lines were subcultured for 2 weeks before assay using trypsin EDTA (Lonza, USA). Their viability and counting were detected by trypan blue stain and hemocytometer. Wi-38 and Vero were seeded in 96 well culture plate as 1x104 cells per well and incubated at $37^{\circ} \mathrm{C}$ in $5 \% \mathrm{CO} 2$ incubator. After $24 \mathrm{~h}$, cells were treated with the serial dilutions of $\mathrm{CC}(0,6.25,12.5,25,50$ and $100 \mu \mathrm{g} / \mathrm{ml})$. After $72 \mathrm{~h}$ incubation in $5 \% \mathrm{CO} 2$ incubator, 20 $\mu \mathrm{l}$ of MTT solution $(5 \mathrm{mg} / \mathrm{ml})$ was added to each well and incubated at $37^{\circ} \mathrm{C}$ for $4 \mathrm{~h}$ in $5 \% \mathrm{CO} 2$ incubator. MTT (Sigma, USA) solution was removed and the insoluble blue formazan crystals trapped in cells were solubilized with $150 \mu 1$ of $100 \% \mathrm{DMSO}$ at $37^{\circ} \mathrm{C}$ for $10 \mathrm{~min}$. The absorbance of each well was measured with a microplate reader (BMG LabTech, Germany) at $570 \mathrm{~nm}$. The safe dose (EC100) was estimated by the Graphpad Instat software as the concentration of C. colocynthis fruit extract at $100 \%$ cell viability.Additionally, morphological changes of C. colocynthis fruit extract treated normal human and mammalian cells were investigated in comparison with untreated control cells using phase contrast microscope supplemented with digital camera (Olympus, Japan).

\section{3- Determination of free radical antioxidant activity by DPPH of CCE}

Determination of the free radical scavenging activity by the 1, 1-Diphenyl-2-picrylhydrazyl (DPPH) Radical scavenging activities of various concentrations of C. colocynthis fruit extract were assayed according to Braca et al. (2001). All tested samples were incubated with DPPH $(0.004 \%$ in methanol) in the dark for $30 \mathrm{~min}$. Then the absorbance was measured at $517 \mathrm{~nm}$. The percent of radical scavenging at each corresponding Log concentrations of each sample was used for calculating the IC50 value (50\% inhibitory concentration) using GraphPad Instat software.

\section{Antimicrobial Activity}

\subsection{Microorganisms and Culture Conditions}

Pathogenic bacteria strains used were; Bacillus cereus EMCC 1006, Staphylococcus aureus EMCC 1351, Escherichia coli ATCC 25922 and Clostridium perfringens. All strains were obtained from Microbiological Resources Center (MERCIN), Faculty of Agriculture, Ain Shams University, Cairo, Egypt. The strains were maintained by; the Department of Food Technology, Arid Lands Cultivation Research Institute, City of Scientific Research and Technological Applications, Egypt in $60 \%$ glycerol/ LB culture at $-80^{\circ} \mathrm{C}$ (Alhejjaj et al., 2010; Hamad et al., 2018).

\subsection{Minimum Inhibitory Concentration (MIC) Determination}

The bacterial strains were grown in nutrient broth at $37^{\circ} \mathrm{C}$. A set of 7 concentration of reconstituted plant water extracts $(100,75,50,25,12.5,6.25$ and $3.1 \mathrm{mg} / \mathrm{mL})$, were examined to determine the minimum inhibitory concentration (MIC) of each against a specific pathogenic strain (Hamad et al., 2015). The zone of inhibition was calculated by measuring the diameter of the inhibition 
zone around the well $(\mathrm{mm})$, including the well diameter. The readings were taken in three different fixed directions in all triplicates and the average values were tabulated (Hamad et al., 2018).

\section{5- Determination of Total Phenolic Content in Citrullus Colocynthis Extract}

The total phenolic content of the Citrullus Colocynthis extract was determined by Folin-Ciocalteu spectrophotometric method according to Bhagyashri et al., (2013). The $0.1 \mathrm{~mL}$ of Folin-Ciocalteu reagent was added to $2 \mathrm{~mL}$ of the Citrullus colocynthis extract. The mixture was allowed to stand for $15 \mathrm{~min}$. Then, $3 \mathrm{~mL}$ of saturated sodium carbonate $2 \%(\mathrm{Na} 2 \mathrm{CO} 3)$ was added. The mixture was allowed to stand for $30 \mathrm{~min}$ at room temperature and the total phenolic content was determined spectrophotometrically (Labo America, USA) at $760 \mathrm{~nm}$. Gallic acid was used as a standard. Total phenol values are expressedin terms of $\mathrm{mg}$ of Gallic acid equivalent per gram of the Sausage sample using the linear regression equation obtained from the standard Gallic acid calibration curve; $\mathrm{y}=$ 28.291x +0.4643 . All samples were analyzed in triplicates (Hamad et al., 2018).

\section{6-Total flavonoids content}

The total flavonoids content of each aqueous extracts (CCE1, CCE2 and CC3) of C. colocynthis fruits were determined by a colorimetric method. Each sample $(0.5 \mathrm{~mL})$ containing $1 \mathrm{mg} / \mathrm{mL}$, was mixed with $2 \mathrm{~mL}$ of distilled water and $0.15 \mathrm{~mL}$ of NaNO2 solution (15\%). After 6 min, $0.15 \mathrm{ml}$ of $\mathrm{AlCl} 3(10 \%)$ and $2 \mathrm{~mL}$ of $\mathrm{NaOH}(4 \%)$ solutions were added. Immediately, water was added to bring the final volume to $5 \mathrm{~mL}$ and tubes were thoroughly mixed and incubated for $15 \mathrm{~min}$ at room temperature. The absorbance was measured at $510 \mathrm{~nm}$. Results were expressed as catechin equivalent per gram of dry extract (mg Cat eq/g) (Benariba et al., 2013; Belkacem et al., 2014).

\section{7- Preparations of beef luncheon as food supplement application}

Luncheon rolls meat preparation: The luncheon roll meat batter was prepared according to the following formula: $75 \%$ minced beef meat, $10 \%$ corn oil, $2.5 \%$ salt, $4 \%$ gelatin, $1 \%$ spices, $1 \%$ ground garlic, $2 \%$ onion, $4 \%$ wheat flour, $0.02 \%$ proceed chees isolate and $20 \%$ ice. The procedure used in preparation of luncheon roll was carried out according to the protocol described by Ferial et al. (2011) with some modifications. Processing of the batter involved blending the frozen minced meat and oil with the other ingredients. The prepared luncheon meat batter was divided into 3 parts 250 gm each with adding 300ppm from CCE1 and CCE2 and one sample without CCE addition. The samples were numeric as following no. 1 for CCE1 and 2 For CCE2 sample which was high safety samples in results cytotoxicity determination and 3 for control sample without any additives. Each was mixed well to be homogenous and stuffed into round bottom tubes $5-\mathrm{cm}$ diameter and $15-\mathrm{cm}$ long, fibrous casings (about $250 \mathrm{~g}$ each) and sealed Luncheon roll meat samples(1-4) were cooked in a air oven set at $100^{\circ} \mathrm{C}$, then held under refrigeration $\left(\sim 1-4^{\circ} \mathrm{C}\right)$ for $10 \mathrm{~h}$. After processing, the luncheon roll meat samples were stored at $4^{\circ} \mathrm{C}$. The sensory evaluation analyses were performed on luncheon samples at different additives.

\section{8-Sensory evaluation:}

The sensorial criteria (color .taste, odder, texture and Over all acceptance) of the three ( 2 high safety samples CCE1, CCE2 and control) luncheon samples under investigation were evaluated by 10 untrained panelists. Luncheon samples were cut into $2 \mathrm{~mm}$ thick slices and served in numerically-coded glass petri dishes. Each panelist received four coded samples (one from each tested samples) then independently evaluated the luncheon meat for texture, odder, color and taste using a 5-point hedonic scale $(0-3=$ extremely poor, $4-5=$ poor, $6-7=$ acceptable, $8-9=$ good, $10=$ excellent $)$, according to the described method by Lavrova and Krilov, (1975) and Martinez, et al. (2004).

\section{Statistical analysis:}

The methods of conventional statistical were used to calculate means and standard deviations. All the measurements were replicated 10 times and the data are presented as mean $\pm \mathrm{SD}$. The acceptance of panelists data were subjected to analysis SPSS (1997) Significance was defined (0.05>p) (Martinez, et al., 2004). 


\section{Results and Discussion}

\section{Cytotoxicity effect of $C$. colocynthis fruit extract using MTT assay}

The data in table 1 showed that the EC100 (ug/ml) of CCE influence on proliferation of wi-38 \& vero normal cell line and illustrate effect of EC100 of CCE 1, CCE2 and CCE3 on proliferation of normal wi38 \& Vero cell line. Results reveal that CCE1 \& 2 exhibit highest EC100 value in both Wi38 $\&$ vero normal cell line compared to CCE which give the lowest value in both cell line. It is well known that the highest EC100 value indicates the highest safety of the tested extracts on the proliferation of normal cells. And so, CCE1 \& 2 exhibit the safety on the viability of wi38 \& Vero cells, with EC100 more 310 and more $450 \mathrm{ug} / \mathrm{ml}$ respectively amongst the other tested extract CCE. These results of safety extracts indicate capability to use these two extracts in applied product of food technology as safe ingredient component these results agreed with Jayaraman and Christina (2013) whose reported, no toxic effect was reported at doses up to 7-10 times of effective dose of CCE.

Table 1: The $\mathrm{EC}_{100}(\mu \mathrm{g} / \mathrm{ml})$ of C. colocynthis fruit extract on the proliferation of normal cells

\begin{tabular}{ccc}
\hline Samples & Wi-38 & Vero \\
\hline F1 & $220.83 \pm 7.93^{\text {cd }}$ & $254.28 \pm 2.63^{\mathrm{d}}$ \\
F2 & $237.25 \pm 1.42^{\mathrm{c}}$ & $251.22 \pm 2.89^{\mathrm{d}}$ \\
F3 & $71.889 \pm 7.36^{\mathrm{f}}$ & $130.83 \pm 1.72^{\mathrm{f}}$ \\
F4 & $198.71 \pm 0.88^{\mathrm{d}}$ & $143.25 \pm 2.37^{\mathrm{f}}$ \\
CCE 1 & $\mathbf{3 1 3 . 4 3} \pm \mathbf{3 . 3 2}^{\mathrm{a}}$ & $\mathbf{4 5 1 . 4 8}_{\mathbf{6 . 1 6}}$ \\
CCE 2 & $\mathbf{3 1 0 . 3 6} \pm \mathbf{3 . 4 2}$ & $\mathbf{5 1 5 . 8 4} \pm \mathbf{3 . 2 0}^{\mathbf{a}}$ \\
CCE 3 & $259.38 \pm 4.93^{\mathrm{bc}}$ & $297.10 \pm 4.13^{\mathrm{c}}$ \\
CCE 4 & $115.30 \pm 4.15^{\mathrm{e}}$ & $188.05 \pm 2.72^{\mathrm{e}}$ \\
\hline
\end{tabular}

All values are expressed as mean \pm standard error of mean (SEM). Different letters indicate significantly different at $p<0.05$.

\section{Free radical antioxidant activity by DPPH of CCE}

Based on the lowest $\mathrm{IC}_{50}$ value of DPPH scavenging activity have the highest antioxidant activity, CCE 1 and CCE 2 exhibited the strongest potential for radical scavenging at $<460 \mu \mathrm{g} / \mathrm{ml}$ comparing to other tested extracts (Table 2). In the present study, the DPPH scavenging activity of the other samples increased in the following order: CCE $4>\mathrm{CCE} 3>\mathrm{F} 3>\mathrm{F} 4>\mathrm{F} 1>\mathrm{F} 2$. So, F2 had the lowest antioxidant activity amongst all extracts .because the CCE 1, 2 that fist extractions which have more phenolic flavonoid components. This results was in harmony with Sunil (2008).

Table 2: $\mathrm{IC}_{50}$ values $(\mu \mathrm{g} / \mathrm{ml})$ for DPPH scavenging activity of $C$. colocynthis fruit extract

\begin{tabular}{cc}
\hline Sample & IC50 $^{5}$ \\
\hline F1 & $877.118 \pm 3.162^{\mathrm{e}}$ \\
F2 & $1527.114 \pm 6.11^{\mathrm{f}}$ \\
F4 & $813.03 \pm 6.73^{\mathrm{d}}$ \\
CCE 1 & $863.960 \pm 1.35^{\mathrm{e}}$ \\
CCE 2 & $438.890 \pm 5.6^{\mathrm{a}}$ \\
CCE 3 & $458.601 \pm 4.919^{\mathrm{a}}$ \\
CCE 4 & $715.939 \pm 4.151^{\mathrm{c}}$ \\
\hline
\end{tabular}

\section{Antibacterial activity}

Data in Table (3) shows antibacterial activity of three CCE against four pathogenic bacteria. Inhibition zones related to CCE show that all extracts have antibacterial activity against studied pathogenic bacteria. On the other hand CCE was more potential against pathogenic bacteria compared to other two extracts CCE1, 2, 3. . Where inhibition zones are 20,17, 12, 9 compared to 15, 13, 7, 6 and 10, 6, 3, 4 mm against Bacillus cereus, Staphylococcus aureus, E. coli, \& Clostridium p. respectively. In addition, Bacillus cereus was more affected by CCE compared to other pathogenic bacteria, meanwhile Staph was moderate affected followed by E. coli and the lowest affected recorded to Close. These results reveal that CME have different antibacterial activity against pathogenic bacteria depending on pathogenic type and extraction protocol as shown. Moreover, results recommended to 
apply CCE as natural antibacterial extract to inhibit most pathogenic bacteria especially bacillus which record highest zone inhibition among all four pathogenic bacteria. In this connection this inhibition effect happened by CCE could be attributed to natural phytochemical constituents found in these extracts that stop or delay bacterial growth. These results are in accordance with Gurudeeban et al. (2011) and Gamal et al. 2017) who found that ethanolic extract of Citrullus colocynthus gives broad spectrum antimicrobial activity against 16 clinical microorganisms included E. coli \& Staphylococcus aureus.

Table 3: Antibacterial activity of aqueous extracts of Citrullus colocynthis $(100 \mathrm{mg} / \mathrm{ml})$

\begin{tabular}{lccc}
\hline \multirow{2}{*}{ Pathogenic strain } & \multicolumn{3}{c}{ Inhibition zone diameter (mm) } \\
\cline { 2 - 4 } & CCE 1 & CCE 2 & CCE 3 \\
\hline Bacillus cereus EMCC1006 & 20 & 15 & 10 \\
Staphylococcus aureus EMCC1351 & 17 & 13 & 6 \\
Escherichia coli ATCC25922 & 12 & 7 & 3 \\
Clostridium perfringens EMCC1574 & 9 & 6 & 4 \\
\hline
\end{tabular}

\section{4-Inhibition effect of Citrullus colocynthis on pathogenic bacteria.}

The results in Table 4 and fig. 1 showed that the maximum inhibition zone was of Bacillus curuse, Staphylococcus aureus, Escherichia coli, clostridium per fringe, respectively. And maximum inhibition effect of Citrullus colocynthis samples CCE 1, CCE 2, and CCE 3 extract) Respectively .

Table 4: Inhibition zone diameters and MICs of Citrullus colocynthis aqueous extract (CCE1) against bacterial strains

\begin{tabular}{lcccccccc}
\hline \multirow{2}{*}{ Pathogenic strain } & \multicolumn{7}{c}{ Inhibition zone diameter (mm) } \\
\cline { 2 - 8 } & $\mathbf{1 0 0 *}$ & $\mathbf{7 5}^{*}$ & $\mathbf{5 0}^{*}$ & $\mathbf{2 5}^{*}$ & $\mathbf{1 2 . 5}^{*}$ & $\mathbf{6 . 2}$ & $\mathbf{3 . 1}^{*}$ & MIC \\
\hline Bacillus cereus EMCC1006 & 20 & 16 & 11 & 6 & 3 & 1 & ND & 6.2 \\
Staphylococcus aureus EMCC1351 & 17 & 14 & 10 & 5 & 2 & ND & ND & 12.5 \\
Escherichia coli ATCC25922 & 12 & 9 & 5 & 3 & ND & ND & ND & 25 \\
Clostridium perfringens EMCC1574 & 9 & 6 & 4 & 2 & ND & ND & ND & 25 \\
\hline
\end{tabular}

MIC; Minimum Inhibition Concentration *Concentrations of extract and MIC are in $\mathrm{mg} / \mathrm{mL}$ ND; Not detected.
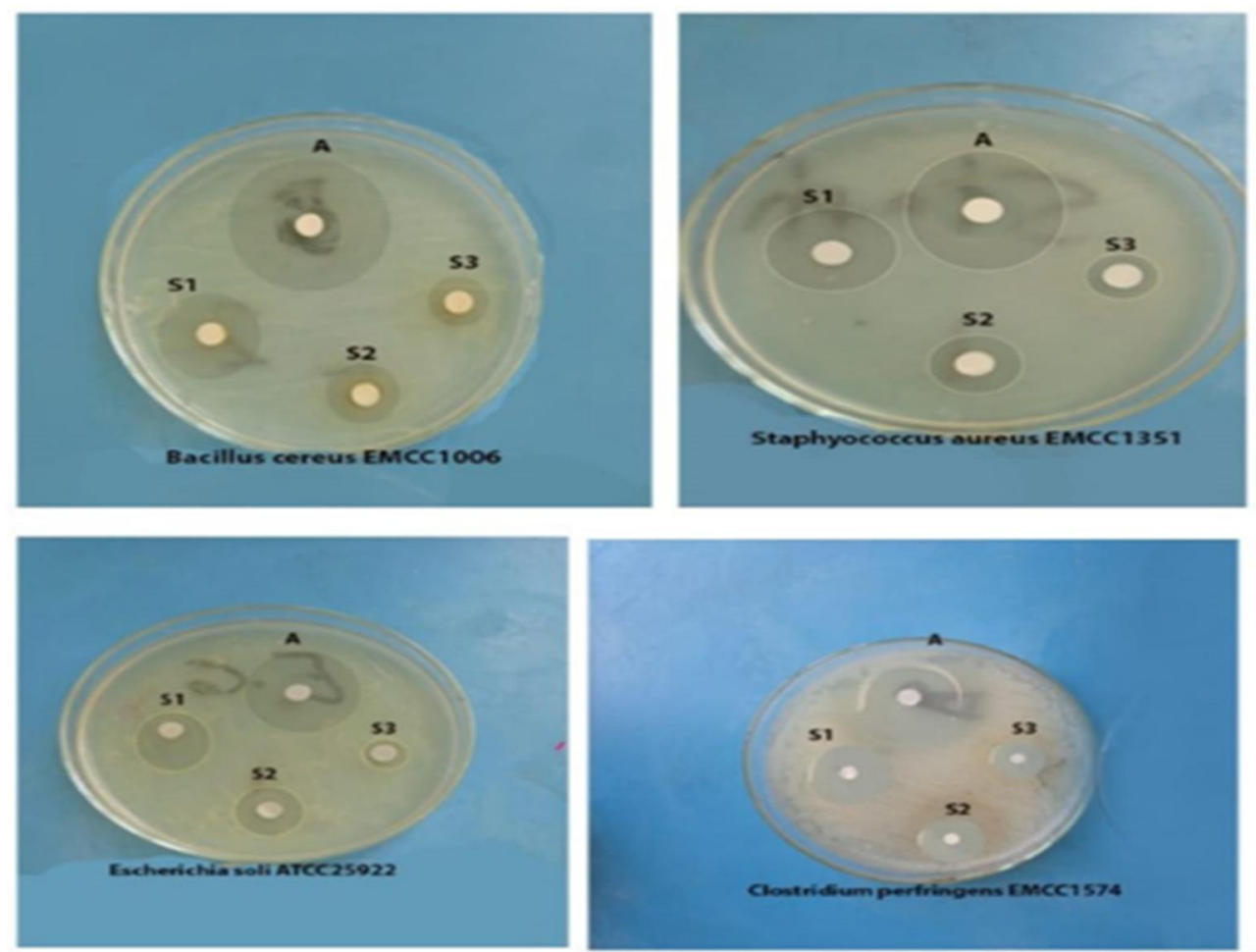

Fig 1: Inhibition zone pictures of Citrullus colocynthis aqueous extract CCE1, 2, 3 against bacterial strains in petri dish 
Represent MIC of CCE1 which record the best inhibition zone against studied pathogenic bacteria. As shown in Table 5 MIC test was ranged from 100 to $3.1 \mathrm{mg} / \mathrm{ml}$. In addition results reveal that MIC wit $6.2 \mathrm{mg} / \mathrm{ml}$ recorded $1 \mathrm{~mm}$ iz against Bacillus cereus. This result confirm CCE1 have antibacterial activity against all four pathogenic bacteria an bacillus cereus was affected by on half of CCE compared to one fold 12.5 in Staphylococcus aureus and four fold $25 \mathrm{mg} / \mathrm{ml}$ in E.coli and Clostridium $p$. This wide range of inhibition zones related to different CCE1 concentration permit to use CCE1 to inhibit different pathogenic bacteria depending on kinds of bacteria up to $25 \mathrm{mg} / \mathrm{ml}$. In addition applied this lower concentration as preservative food additive against pathogenic bacteria. This results were agreed with Al-hejjaj et al. (2010)

\section{Total Phenolic and flavonoids Content}

Total Phenolic Content of Citrullus colocynthis Extract was found in table( 5 ), it were (1.3748, $0.6981,0.4790 \mathrm{~g}$ ) gallic acid equivalent per $100 \mathrm{~g}$ aqueous extract to samples CCE 1, CCE 2 and CCE 3 respectively by using the equation $\mathrm{y}=(28.291 \mathrm{x}+0.4643)$. Results of total phenolic compounds in CCE reveal that phenolic contents were $1.3748,0.6981,0.4790(\mathrm{~g} / 100 \mathrm{ml})$. These values show that extract No.1 was rich in phenolic compounds compare to extracts $2 \& 3$. Thus, this high level of phenolic contents in CCE1 will be more strong in protection against oxidative stress either biotic or abiotic stress. Bhagyashri et al. (2013).

While the results of the Total flavonoids Content in Citrullus Colocynthis Extract found to be $80,54.33$ and $28.33 \mathrm{mg}$ Quercetin equivalent per $100 \mathrm{~g}$ aqueous extract to samples CME 1, CCE 2 and CCE 3 respectively by using the equation $\mathrm{y}=(0.012 \mathrm{x}-0.091)$.

Table 5: Total Phenolic content and Total Flavonoids content of Aqueous extract Citrullus colocynthis

\begin{tabular}{lcc}
\hline Sample & $\begin{array}{c}\text { Total Phenolic content } \\
(\mathbf{m g} / \mathbf{1 0 0 g})\end{array}$ & $\begin{array}{c}\text { Total Flavonoids content } \\
(\mathbf{m g} / \mathbf{1 0 0 g})\end{array}$ \\
Aqueous extract CCE 1 & 1.3748 & 80 \\
Aqueous extract CCE 2 & 0.6981 & 54.33 \\
Aqueous extract CCE 3 & 0.4790 & 28.33 \\
\hline
\end{tabular}

\section{Phytochemical content}

Phytochemical constituents in water extract of CM fruit were presented in Table (6). Results reveal that 13 natural compounds were detected in aqueous extract of CM. Preliminary phytochemical screening of the plant extract showed the presence of terpinoids, flavonoids, glycosides, alkaloids and tannins and phenolic this results agreed with Jayaraman and Christina (2013), but they disagreed in glycosides presence may be to used different aqueous solution for extraction in this study we used water for extraction but the other author used methanol

Table 6: Phytochemical screening of highest safety C. colocynthis extract

\begin{tabular}{lcc}
\hline Chemical Constituent & CCE1 & CCE2 \\
\hline Alkaloid & + & + \\
Tannins & +++ & ++ \\
Saponins & + & + \\
Flavanoid & + & + \\
Terpenoid & ++ & + \\
Glycosides & + & + \\
Steroid & + & + \\
Flavonoids & + & + \\
Redusing sugars & - & - \\
Carbohydrate & + & + \\
Protein & - & - \\
Amino Acid & + & + \\
Total Phenolic compound & + & + \\
\hline
\end{tabular}

\section{Sensory evaluation of luncheon}

Data in Table 7. Showed that acceptance grade of sensory evaluation of luncheon with . The CCE1, 2 were moderate acceptable compare with sample control. Sensory parameter include color, 
taste, odder, texture and overall acceptance. . In addition, grades of sensory evaluation for CCE1 \& 2 gave the same acceptable for panelists and have not significant difference between them. This result reveal that CCE either extracted by soaking or boiling, seeds can caught more bitter components into the plant cells more than which outcome from the plant cells. Generally, the control sample was near panelists acceptance grade with CCE1 (Ferial et al., 2011; Martinez et al., 2004).

Table 7: Sensory evaluation of luncheon content 300 ppm of CCE1, CCE2 and control

\begin{tabular}{lccccc}
\hline Sample no. & $\begin{array}{c}\text { Colour } \\
(\mathbf{0 - 1 0 )}\end{array}$ & $\begin{array}{c}\text { Taste } \\
(\mathbf{0 - 1 0})\end{array}$ & $\begin{array}{c}\text { Odder } \\
(\mathbf{0 - 1 0})\end{array}$ & $\begin{array}{c}\text { Texture } \\
(\mathbf{0 - 1 0 )}\end{array}$ & $\begin{array}{c}\text { Over all acceptance } \\
(\mathbf{0 - 1 0})\end{array}$ \\
\hline CCE1 & $5.4^{\mathrm{a}}$ & $5.8^{\mathrm{a}}$ & $6.4^{\mathrm{a}}$ & $6.6^{\mathrm{b}}$ & $6.1^{\mathrm{b}}$ \\
CCE2 & $6.6^{\mathrm{b}}$ & $6.8^{\mathrm{a}}$ & $6.7^{\mathrm{a}}$ & $6^{\mathrm{b}}$ & $6.2^{\mathrm{ab}}$ \\
Control 4 & $7.3^{\mathrm{a}}$ & $7.4^{\mathrm{b}}$ & $7.4^{\mathrm{a}}$ & $7.4^{\mathrm{b}}$ & $7.6^{\mathrm{a}}$ \\
\hline
\end{tabular}

Sample 4= control without any extract, Sample $1=$ with CCE1 extract, Sample 2=with CCE2 extract, All values are mean (SD). Means within column with different letters are significantly different $(\mathrm{P}<0.05)$.

\section{Conclusion}

The Data Showed that can make a lot of acceptable food applications with C. colocynthis extracts CCE1, 2 have moderate sensory evaluation of samples and have a lot of antioxidants, flavonoids and more phenols. We can benefit from the CCE plant as a food supplement, a medicinal compound, and a food preservative.

\section{Reference}

Al-hejjaj, M.Y., Y.A. Alhurba and S.A. Mohamad, 2010. Study of alkaloid extract from Citrullus colocynthis fruit and its antimicrobial activity screening. Journal of Basrah Researches, Sciences. 36, (4): 42- 47.

Belkacem, N., R. Djaziri, F. Lahfa, I.A. El-Haci, Z. Boucherit, 2014. Phytochemical screening and in vitro antioxidant activity of various Punica granatum 1 peel extracts from Algeria: a comparative study. Phytothérapie, 12: 372-9.

Belsem, M., M. Zohra , B.H. Ehsen, F. Nadia Fenina, B. Abderrahman and A. Mahjoub , 2010. Screening of analgesic and anti-inflammatory activities of Citrullus colocynthis from southern Tunisia . Journal of Ethnopharmacology , 128: 15-19

Benariba, N., R. Djaziri, W. Bellakhdar, N. Belkacem, M. Kadiata and W.J. Malaisse, 2013. Phytochemical screening and free radical scavenging activity of Citrullus colocynthis seeds extracts. Asian Pac J Trop Biomed., 40-35:3(1).

Bhagyashri, T., S. Poonam and W. Minakshi, 2013. Phytochemical Screening and Determination of Total Phenolic Content of Citrullus colocynthis Linn. International Journal of Pharmaceutical and Phytopharmacological Research, 3 (1): 44-45.

Braca, A., N.D. Tommasi, L.D. Bari, C. Pizza, M. Politi, and I. Morelli, 2001. Antioxidant principles from Bauhinia terapotensis. Journal of Natural Products, 64: 892-895.

Brand, W., M.E. Cuvelier and C. Berset, 1995. Use of a Free Radical Method to Evaluate Antioxidant Activity. Food Sci. Technol., 28: 25-30.

Ferial, M. Abu-Salem, Esmat A. Abou-Arab, Hayam M. Ibrahim and Azza A. Abou-Arab, 2011. Effect of Adding Green Tea Extract, Thyme Oil and/or their Combination to Luncheon Roll Meat during Refrigerate Storage. Journal of American Science, 7(7).

Gamal, M.H., M.Z. Ahmed, Marwa M. Abu-Serie and E.H. Elsayed, 2018. Detection and Control of Foodborne Pathogenic Bacteria Using Solanum nigrum Extract as Antibacterial in Meat Products. Annual Research \& Review in Biology, 23(6): 1-17.

Gamal, M.H., Amira M.G. Darwish, Marwa M Abu-Serie, and A.E. Sobhy, 2017. Antimicrobial, Antioxidant and Anti-inflammatory Characteristics of Combination (Cassia fistula and Ocimum basilicum) extract as Natural Preservative to Control \& Prevent Food. Contamination. Journal of Food and Nutrition Research, 5(10):771-780.

Gurudeeba, N.S., T. Ramanathan and K. Satyavani, 2011. Characterization of Volatile Compounds from Bitter Apple (Citrullus colocynthis) Using GC-MS. International Journal of Chemical and Analytical Science ISSN: 0976-1206 
Hamad, G.M., T.H. Taha, N.M. El-Deeb, A.M.A. Alshehri, 2015. Advanced trends in controlling Helicobacter pylori infections using functional and therapeutically supplements in baby milk. J. Food Sci. Technol. 52: 8156-8163.

Hassain, A.I., H.A. Rathore, M.Z.A. Sattar, S.A.S. Chatha, S.D. Sarker, and A.H. Gilani , 2014. Citrullus colocynthis (L.) Schrad (bitter apple fruit): A review of its phytochemistry, pharmacology, traditional uses and nutritional potential. Journal of Ethnopharmacology, 155 $(1,8)$ 13: 54-66.

Jayaraman, R. and A.J.M. Christina, 2013. Evaluation of Citrullus colocynthis fruits on in vitro antioxidant activity and in vivo DEN/PB induced hepatotoxicity. International Journal of Applied Research in Natural Products; 6 (1):1-9.

Lavrova, L.P. and V.X. Krilova, 1975. Luncheon meat technology, in Russian. Moscow: Food' Industry, 325-326.

Martinez, O., J. Salmer, M.D. Guill and C. Casas, 2004. Texture profile analysis of meat products treated with commercial liquid smoke flavorings. Food Control, 15:457-461

Mehdi, Q., A. Mojtaba, Z. Ahmad, N.A. Ali, S. Samira and S. Mahmoud, 2018. Phenol removal from aqueous solution using Citrullus colocynthis waste ash . Data in Brief, 18: 620-628

Mohadeseh, O.A., A.B. Abolfazl, M. Hossein, C. Anbardar, D. Aida, E. Iraji, F.M. Salmanpour, H.G. Salar, H.H. Mojtaba and M. Sham, 2020. Effects of Citrullus colocynthis L. in a rat model of diabetic neuropathy.s Journal of Integrative Medicine, 18: 59-67.

Mojtaba, H., H.H. Mohammad, O. Mohadeseh, and S. Mesbah, 2019. Citrullus colocynthis and Its Potential Role against Diabetes and Its Complications Bioactive Food as Dietary Interventions for Diabetes book, Chapter, 32: 495-507.

Mosmann, T., 1983. Rapid colorimetric assay for cellular growth and survival: Application to proliferation and cytotoxicity assays. Journal of Immunological Methods. 65(1):55-63.

Sunil, K.K., K. Manjusha and S.S. Vashishta, 2008. Antioxidant and free radical scavenging potential of Citrullus colocynthis (L.) Schrad. methanolic fruit extract .Acta Pharm. 58215-220

Yang, W.J., G.U. Zhengyi, T. Dilnur, B. Chen, H. Hasimu, C. Liu, J. He, L. Xu, and Y. Mao, 2013. Protection of Citrullus colocynthis Fruit Extracts on Carbon Tetrachloride-induced and Bacillus Calmette-Guerin plus Lipopolysaccharide-induced Hepatotoxicity in Mice. Chinese Herbal Medicines, 5(3): 205-211.

Yushuang, L.B.D., Z. Lu, X. Jingjing, W. Kaibo, H. Huiming and Y.B. Tao, 2020. Norcolocynthenins $\mathrm{A}$ and B, two cucurbitane 3-nor-Triterpenoids from Citrullus colocynthis and their cytotoxicity. Bioorganic Chemistry, 101-104, 045(1-5). 